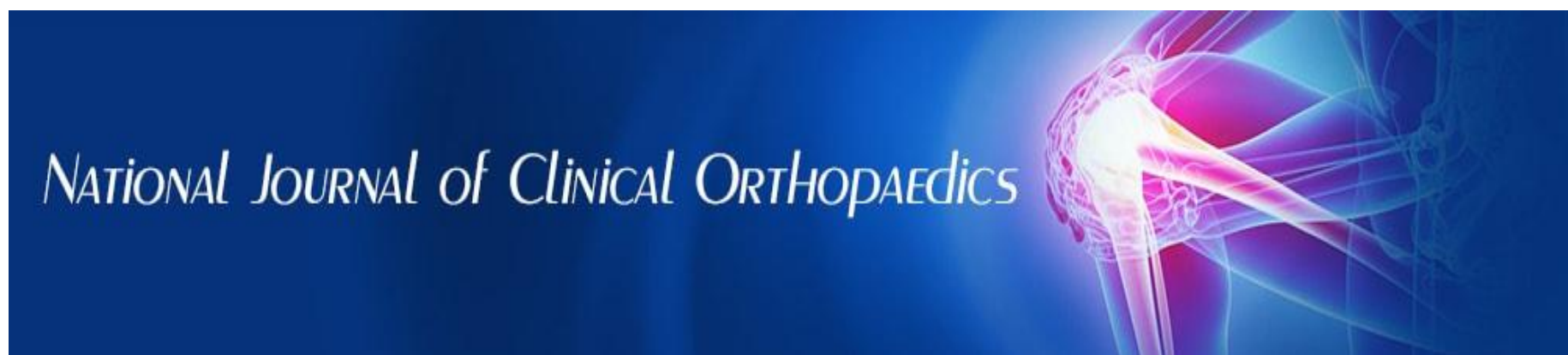

ISSN (P): 2521-3466

ISSN (E): 2521-3474

(C) Clinical Orthopaedics

www.orthoresearchjournal.com

2019; 3(1): 154-156

Received: 23-11-2018

Accepted: 26-12-2018

Dr. Shivaraj AC

Assistant Professor,

Mahadevappa Rampure Medical College, Kalaburagi, Karnataka, India

Dr. Ullas Mahesh

Assistant Professor,

Rajarajeshwari Medical College,

Bangalore, Karnataka, India
Correspondence

Dr. Ullas Mahesh

Assistant Professor,

Rajarajeshwari Medical College,

Bangalore, Karnataka, India

\section{Operative management of proximal humerus fractures- A clinical study}

\section{Dr. Shivaraj AC and Dr. Ullas Mahesh}

DOI: https://doi.org/10.33545/orthor.2019.v3.i1c.30

\section{Abstract}

Proximal humerus fractures accounts for about 4 to $5 \%$ of all fractures. Treatment of unstable, displaced, and comminuted fractures of the proximal humerus remain challenging. Significant controversy continues regarding the best methods of treating displaced proximal humerus fractures. Various operative procedures are carried out, the recent trend in internal fixation has moved on to locking plates.

Results: The incidence of proximal humerus fractures is increasing. It is a common osteoporotic fracture. Bone density is a predictor of reduction quality and can be readily assessed with anteroposterior views of the shoulder.

Conclusion: A majority of minimally displaced fractures can be treated conservatively with early physical therapy. Treatment for displaced fractures should consider the patient's level of independence, bone quality, and surgical risk factors. Fixation with percutaneous techniques, intramedullary nails, locking plates, and arthroplasty are all acceptable treatment options. There is no clear evidence-based treatment of choice, and the surgeon should consider their comfort level with various procedures during the decision-making process.

Keywords: upper extremity surgery, geriatric trauma, fragility fractures, trauma surgery, osteoporosis

\section{Introduction}

Fractures of the proximal humerus are one of the commonest fractures encountered by an Orthopedician. The incidence of this fracture has significantly increased perhaps due to the increased vehicular traffic \& mechanized life.

The injury is of great importance when it affects the young \& middle age groups of the population. It leads to temporary disability \& loss of working hours. Restoration of function of the limb is of paramount importance.

These fractures usually do not constitute a major therapeutic problem. For most undisplaced \& minimally displaced fractures of the proximal humerus non surgical management is preferred because non union is rare, healing time is short \& infection very uncommon. For more displaced fractures \& osteopenic bone, techniques of internal fixation, which emphasize less disruptive soft tissue dissection \& minimal fixation with wire \& non absorbable sutures have been successful with low complication rate. Even AO type buttress plates are being used, nut they require more soft tissue dissection \& may lead to infection. Severely comminuted \& displaced fractures have been treated with hemiarthroplasty.

In fractures treated conservatively or surgically minimal amount of malunion is cosmetically \& functionally acceptable.

Most studies indicate that for the majority of good results of fractures of this region are obtained by conservative methods. Some studies state that operative treatment is better, depending on type of fracture \& quality of the bone. Management of these fractures is associated with some morbidity \& undesirable sequelae. They include complications like avascular necroisis, malunion, nonunion, infection, neurovascular injury, loss of motion of shoulder from adhesive capsulitis, chronic oedema, elbow stiffness \& atrophy of the soft tissues of the immobilized limb causing significant disability during healing \& afterwards.

\section{Aims and objectives}

- To study etiology \& pattern of fractures of the proximal end of humerus. 
- To study various modalities of operative management \& to compare results with standard studies \& draw conclusions.

\section{Materials and methods}

Our study was conducted for three years. We studied 40 patients with proximal humerus fractures, regarding the cause of the fracture, modality of treatment, recovery, the complications \& eventual outcome in terms of shoulder mobility, pain, strength \& activity as compared with other side.

\section{Inclusion criteria}

Fractures of proximal end of humerus in adults.

\section{Exclusion criteria}

- Patients below 18 years

- Fractures more than 3months old

- Patients with minimally displaced fractures according to Neer's classification - < $1 \mathrm{~cm}$ displacement \& <45 degree angulation

- Severe osteopenia.

- Patients in whom the functional demands are low.

\section{Observations and results}

Table 1: Age distribution

\begin{tabular}{|c|c|}
\hline Age in years & No of cases \\
\hline $18-20$ & 02 \\
\hline $21-30$ & 03 \\
\hline $31-40$ & 08 \\
\hline $41-50$ & 07 \\
\hline $51-60$ & 11 \\
\hline $61-70$ & 07 \\
\hline $71-80$ & 02 \\
\hline $81-90$ & 00 \\
\hline$>90$ & 00 \\
\hline Total & 40 \\
\hline
\end{tabular}

Fractures were seen in all age groups, but were common in age group of 41-60 years (45\%). As depicted in Fig 1.

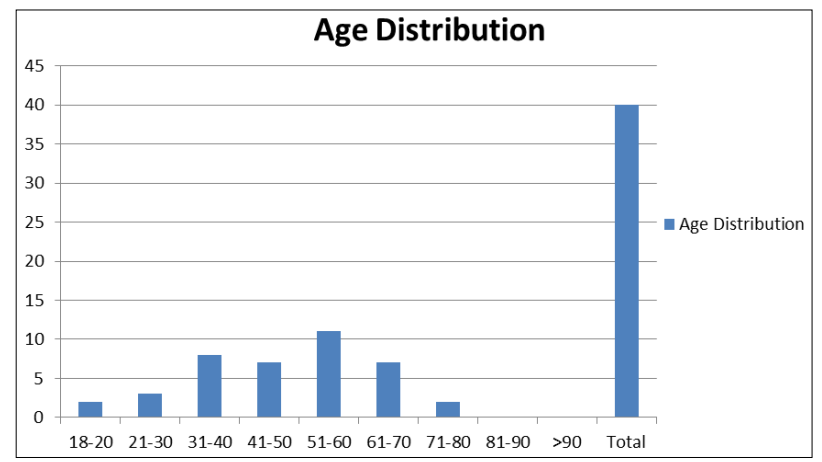

Fig 1: Age distribution

Table 2: Sex Ratio of Patients

\begin{tabular}{|c|c|}
\hline Sex & No of Patients \\
\hline Male & 24 \\
\hline Female & 16 \\
\hline Total & 40 \\
\hline
\end{tabular}

The incidence of fractures of proximal Humerus, was more common in males $(60 \%)$. As depicted in Fig 2.

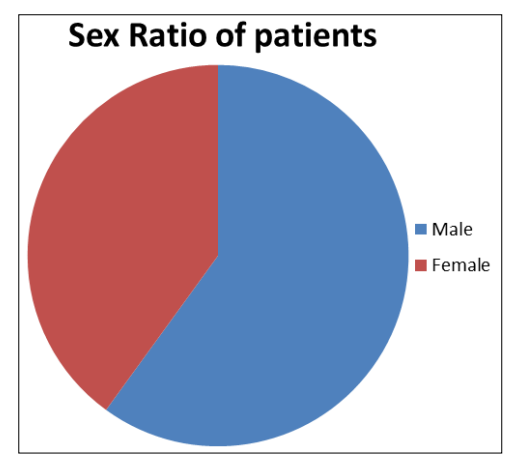

Fig 2: Sex Ratio of Patients

\section{Discussion}

Fractures of the proximal humerus are one of the most common injuries encountered by orthopaedic surgeons. Theses fractures being described about two centuries back, even before the invention of radiography, have shown various trends in their management. Due to awareness of its complexity \& complications, these fractures have stimulated a growing interest in finding the optimal treatment. An anatomical reduction \& good rehabilitation is a strong predictor for good functional outcome.

Earlier these fractures were considered simple and were managed by plaster cast technique, slings \& slabs, but recent advances in understanding of anatomy, good surgical skills \& better instrumentation has lead to various modalities for the treatment of theses fractures like percutaneous pinning, external fixation, bone grafting or bone cement supplements, plate fixation or Prosthetic replacement.

We have treated 40 cases of fractures of proximal humerus surgically and accessed the outcome using Neers shoulder scoring system.

Age of the patients was ranging from 18 years of minimum to 75 years of maximum with an average age of 49 years. As shown in Table 3. The average age in western literature was higher the reason for this was that we have included only those cases that have been operated and they generally tend to belong, to a younger age group \& also since most common cause of injury was MVA, which is commoner in younger age group.

Table 3: Age of the patients was ranging from 18 years of minimum to 75 years of maximum with an average age of 49 years.

\begin{tabular}{|c|c|}
\hline & Average age \\
\hline Our study & 49 years \\
\hline Palvanen et al. & 62 years \\
\hline Horak et al. & 53 years \\
\hline
\end{tabular}

In our study there were 24 males $(60 \%)$ and 16 females $(40 \%)$ and male to female ratio of the patients was $3: 2$. In studies it has been shown that women are more commonly affected with exception of greater tuberosity fractures which are common in men.

Table 4: Our study showed the involvement of right side in 24 cases $(60 \%)$ and 16 cases $(40 \%)$ on left side and ratio was 3:2

\begin{tabular}{|c|c|}
\hline & Male to Female ratio \\
\hline Our study & $3: 2$ \\
\hline Palvanen et al. & $1: 1.5$ \\
\hline Horak et al. & $2: 1$ \\
\hline
\end{tabular}


Our study showed the involvement of right side in 24 cases $(60 \%)$ and 16 cases $(40 \%)$ on left side and ratio was 3:2, as shown in Table 4.

In studies done by various authors there were similar findings. In our study the main mechanism of injury is motor vehicular accident in 26 cases $(65 \%)$ and fall includes 14 cases $(35 \%)$.

Thus showing high velocity injury as the main mechanism.

Comparing our study with the published series, we find that the emergence of high velocity injury due to motor vehicular accidents has changed out look towards these fractures.

Out of theses 40 patients, two had intertrochanteric fracture femur, two had fracture tibia, one had fracture shaft femur, one had supracondylar fracture femur, one had D6 vertebral fracture, one had bimalleolar fracture ankle and one had fracture phalanx.

\section{Conclusion and summary}

All the patients were evaluated on the basis of Neer's scoring system and following conclusions were drawn.

- The most common etiology of the fracture of proximal humerus was motor vehicular accident of some kind

- The most common type of fracture seen in our study was the two part surgical neck fracture

- Young adults with displaced surgical neck humerus fractures, if stable after closed reduction, can be treated conservatively. If unstable, it is ideal to do open reduction and internal fixation.

- In older individuals with surgical neck humerus it is good to fix with percutaneous ' $\mathrm{K}$ 'wires, keeping in mind about quality of bone (osteoporosis) and also to shorten the period of surgery.

- Displaced greater tuberosity fractures should always be fixed internally with screws `after open reduction.

- Displaced three part fractures in young patients need anatomical reduction and are fixed internally with percutaneous ' $\mathrm{K}$ ' wires or plate.

- Literature says anatomical neck fractures of proximal humerus account for only $0.54 \%$ of proximal humeral fractures. Displaced anatomical neck fractures cause complete disruption of blood supply to the articular segment. The success rate of closed pinning and headless screw fixation is very less. The chance of avascular necrosis of humeral head increases by 5times, in these type of fractures. The only preferred treatment for displaced anatomical neck fracture is primary hemiarthroplasty.

\section{References}

1. Court-Brown CM, Caesar B. Epidemiology of adult fractures: a review. Injury. 2006; 37(8):691-697. doi:10.1016/j.injury.2006.04.130. [PubMed]

2. Calvo E, Morcillo D, Foruria AM, Redondo-Santamaría E, Osorio-Picorne F, Caeiro JR. Nondisplaced proximal humeral fractures: high incidence among outpatient-treated osteoporotic fractures and severe impact on upper extremity function and patient subjective health perception. J Shoulder Elbow Surg. 2011; 20(5):795-801. doi:10.1016/j.jse.2010.09.008. [PubMed]

3. Palvanen M, Kannus P, Niemi S, Parkkari J. Update in the epidemiology of proximal humeral fractures. Clin Orthop. 2006; 442:87-92. [PubMed]

4. Savin DD, Zamfirova I, Iannotti J, Goldberg BA, Youderian AR. Survey study suggests that reverse total shoulder arthroplasty is becoming the treatment of choice for fourpart fractures of the humeral head in the elderly. Int Orthop. 2016; 40(9):1919-1925. doi:10.1007/s00264-016-3227-y.
[PubMed]

5. Okike K, Lee OC, Makanji H, Harris MB, Vrahas MS. Factors associated with the decision for operative versus non-operative treatment of displaced proximal humerus fractures in the elderly. Injury. 2013; 44(4):448-455. doi:10.1016/j.injury.2012.09.002. [PubMed]

6. McLaurin TM. Proximal humerus fractures in the elderly are we operating on too many? Bull Hosp Jt Dis N Y N. 2004; 62(1-2):24-32. [PubMed]

7. Handoll HHG, Ollivere BJ, Rollins KE. Interventions for treating proximal humeral fractures in adults. Cochrane Database Syst Rev. 2012; 12:CD000434. doi:10.1002/14651858.CD000434.pub3. [PubMed]

8. Handoll HH, Keding A, Corbacho B, Brealey SD, Hewitt C, Rangan A. Five-year follow-up results of the PROFHER trial comparing operative and non-operative treatment of adults with a displaced fracture of the proximal humerus. Bone Joint J. 2017; 99-B(3):383-392. doi:10.1302/0301620X.99B3.BJJ-2016-1028. [PMC free article] [PubMed]

9. Boileau P, Walch G. The three-dimensional geometry of the proximal humerus. J Bone Joint Surg Br. 1997; 79 $\mathrm{B}(5): 857-865$. [PubMed]

10. Murachovsky J, Ikemoto RY, Nascimento LGP, Fujiki EN, Milani C, Warner JJP. Pectoralis major tendon reference (PMT): a new method for accurate restoration of humeral length with hemiarthroplasty for fracture. J Shoulder Elbow Surg. 2006; 15(6):675-678. doi:10.1016/j.jse.2005.12.011. [PubMed] 